\title{
Molecular and cellular stratagem of brain metastases associated with melanoma (Review)
}

\author{
ANA-MARIA BUGA ${ }^{1,2}$, ANCA OANA DOCEA ${ }^{2}$, CARMEN ALBU $^{3}$, RAMONA DENISE MALIN $^{3}$, \\ DACIANA ELENA BRANISTEANU ${ }^{4}$, GABRIEL IANOSI $^{5}$, SIMONA LAURA IANOSI $^{6}$, \\ ANDREI IORDACHE ${ }^{7}$ and DANIELA CALINA ${ }^{7}$
}

\begin{abstract}
Departments of ${ }^{1}$ Functional Science, ${ }^{2}$ Toxicology, and ${ }^{3}$ Neurology, University of Medicine and Pharmacy of Craiova, 200349 Craiova; ${ }^{4}$ Department of Dermatology, University of Medicine and Pharmacy 'Gr. T. Popa', 700115 Iasi;

Departments of ${ }^{5}$ Surgery, ${ }^{6}$ Dermatology, and ${ }^{7}$ Clinical Pharmacy, Dermatopharmacy and Cosmetology, University of Medicine and Pharmacy of Craiova, 200349 Craiova, Romania
\end{abstract}

Received September 6, 2018; Accepted December 17, 2018

DOI: $10.3892 / \mathrm{ol} .2019 .9933$

\begin{abstract}
Tumors of the central nervous system are the most prevalent complications of melanoma, especially in the late stage of disease. Melanoma, lung and breast cancer are the leading cause of secondary tumors in the brain, the majority of them having a poor outcome. Brain dissemination is developed in half of stage IV melanomas and these cases can increase up to $75 \%$, having a major impact on the quality of life. This review will focus on recent findings that provide new ways to potentially prevent brain metastases in malignant melanoma. The key of these findings is based on the heterogeneity of the melanoma and of the brain metastases at genetic levels. This new era of technologies provides new tools in understanding the dissemination mechanisms of malignant cells. The cellular and molecular changes, the immune status of the patient and the blood-brain barrier permeability are key regulators of cancer cell dissemination. Understanding these mechanisms can render new hope in preventing brain metastases by focusing on melanoma and new pharmacologic approaches.
\end{abstract}

\section{Contents}

1. Introduction

2. $\mathrm{BBB}$ as barrier in the management of BM patients

3. Biomarkers in melanoma brain metastasis prediction

4. Translational and clinical studies targeting BM specific molecule in melanoma

5. Conclusion

Correspondence to: Dr Anca Oana Docea, Department of Toxicology, University of Medicine and Pharmacy of Craiova, 2 Petru Rareş Street, 200349 Craiova, Romania

E-mail: ancadocea@gmail.com

Key words: melanoma, brain metastases, blood-brain barrier, immune status

\section{Introduction}

Cutaneous melanoma is one of the most aggressive types of skin cancer that has its origins in cutaneous melanocytes, especially among the white population. Recent epidemiological data showed an increased incidence in Europe (13.2 new cases for 100.000 persons) (1).

Melanoma progression depends on many factors such as: i) Accumulation of genetic mutation that promotes dissemination in other organs; ii) the key factors that allow cell survival to metastatic sites. The central nervous system (CNS) tumors have the most frequent complications in the evolution of many types of cancers. Melanoma, lung and breast cancer are the leading cause of brain secondary tumors with poor outcome. Brain dissemination is associated with stage IV melanoma in $>60 \%$ of cases, having a poor neurological outcome or increased incidence of psychiatric disorders, with a major impact on the quality of life (1).

Due to the progress of neuroimaging techniques there can be an early discovery of asymptomatic brain secondary tumors that used to be underdiagnosed before. This can be an explanation for the increased incidence of brain dissemination over the past decades. The length of time needed from the beginning of the carcinogenesis process until effective intervention can be critical for minimizing irreversible CNS lesions. Therefore, we need to implement an efficient multimodal approach of brain secondary tumor management that has to take into consideration: i) The specific physiological, biochemical and molecular pattern of BM; ii) the structural and biological barriers developed to create a highly protective environment.

Many research studies were focused on stage IV melanoma with brain metastases in order to develop an effective treatment protocol, but many of them have failed in clinical trials. One important factor that can have a major impact in the clinical management of melanoma is to properly identify the risk factors that can promote the BM development (2). Also, since it is well-known that the melanoma cells have a higher potential to disseminate into the brain, understanding the cellular and molecular mechanisms that allow these cells 
to disseminate and survive in the CNS microenvironment is crucial for the future of clinical management in these patients.

Previous studies have shown that age, sex and race are important factors (besides melanoma staging) that contribute to a certain variability when it comes to the incidence and drug resistance of BM. Men are associated with a higher incidence (79\% of cases were reported in males) than women, probably due to epigenetic factors (3-5) or specific sex-associated metabolic pathways. Identifying a specific genetic and epigenetic pattern can be the key in preventing the BM in order to extend the lifespan and to improve the quality of life in melanoma patients.

Therapeutic options for BM associated with melanoma are limited. The most frequent approach for BM includes local surgical intervention for tumor resection, radiation therapy or stereotactic radiosurgery. Lately, new promising therapeutic approaches have been used in clinical management of advanced stage melanoma (e.g., immunological therapies). Due to BM drug resistance, recent studies were focused on developing systemic agents that can be effective in BM treatment and that can achieve the optimal therapeutic concentration at tumor site, many of them based on nanoparticles $(6,7)$. Despite the sustained effort, some progress has been made, but we still do not have an effective therapeutic strategy in BM management because most of the nanoparticle-based therapies have many effects (8-11).

However, some of the potential factors that contribute to unsuccessful results in systemic drug delivery can be the high selective permeability of brain blood-barrier (BBB), the biochemical properties of the therapeutic agents or the drug toxicity at therapeutic concentration. On the other hand, the molecular pattern of $\mathrm{BM}$ is different from the original cells and these molecular signatures can be a crucial factor in therapeutic management. Therefore, a better understanding of melanoma cell pathogenic profile, especially its genetic mutations, is required.

\section{BBB as barrier in the management of $B M$ patients}

A better understanding of the key molecular mechanisms that are involved in $\mathrm{BBB}$ penetration by cancer cells can provide an efficient model for effective drug design in BM treatment. $\mathrm{BBB}$ is a protective structure that ensures the CNS homeostasis $(10,12)$. However, it is well-established that melanoma it is one of the most spread malignant diseases that is associated with brain secondary tumors (12). A tumor cell needs specific mediators in order to interact, to penetrate the $\mathrm{BBB}$ and to survive and proliferate in a highly selective brain microenvironment.

Penetration of the BBB is an important step in the metastatic process. In order to cross the $\mathrm{BBB}$, melanoma cells promote the synthesis and secretion of growth factors such as vascular endothelial growth factor (VEGF) $(13,14)$. This mechanism is important in allowing the cells to pass the $\mathrm{BBB}$ using the neurovascular niche. BBB integrity is further damaged by proteolytic enzymes such as matrix metalloproteinases (MMPs) or serin proteases $(15,16)$. However, the full mechanism of BBB penetration by melanoma cells is still not understood. Other important factors that modulate chronic inflammation in the brain are activated astrocytes that release pro-inflammatory molecules such as cytokines and chemokines, therefore promoting neuroinflammation.

Previous studies have demonstrated that astrocytes, which are involved in brain regeneration after injuries, could be activated and reprogrammed by melanoma cells in order to support the penetration, survival and proliferation of cancer cells (17-20). Many changes can promote tumor progression and BM. Astrocytes facilitate melanoma cell migration by secreting CCR4 in the presence of astrocyte-secreted soluble factors that promote a better migration of tumor cells (17). Also, astrocytes can be reprogrammed by human brain-metastasizing melanoma cells to express pro-inflammatory factors like cytokine IL-23 and can increase the tumor invasion by MMP2 secretion. However, astrocytes interact with melanoma cells by paracrine signalling that upregulates the secretion of the MMP2 (18).

However, malignant cells interact with neurovascular cells and release signalling molecules that can inhibit the microglial activation and therefore escape the CNS defence strategy (21). The properties of neurovascular cells and mechanisms that act as a protective environment for metastatic cells are still not fully understood (Fig. 1).

\section{Biomarkers in melanoma brain metastasis prediction}

Many studies on BM in melanoma are focused on identifying the gene expression or metabolic profile that are associated with an increased risk of brain secondary tumor formation and that can be used as predictive biomarkers of disease progression (22-26). Nieder et al suggested that a combination of Karnofsky performance status (KPS) and serum lactate dehydrogenase (LDH) level significantly predicted survival in BM patients (27).

Studies on cell cultures have tried to establish a pattern of metabolic alteration and gene expression profile in melanoma cells. Amino-malonic acid and phosphatidylinositol (PI) levels were increased in melanoma cells, according to a study that was performed by using normal human melanocyte (HEMn-LP), low metastatic melanoma (A375, G361), and highly metastatic melanoma (A2058, SK-MEL-28) cell lines (28). Phosphatidylinositol-3-kinases family (PI3K) is a family of enzymes that play an important role in $\mathrm{PI} 3 \mathrm{~K} / \mathrm{AKT} / \mathrm{mTOR}$ pathway and signal transduction of cell cycle regulation. This pathway promotes cellular growth and differentiation of neural cells (29). PTEN is a natural inhibitor of PI3K/AKT pathway that acts by dephosphorylating PIP3 to PIP2 and decreases AKTs capacity to bind to the cell membrane (30). Zhang et al showed that the malignant cell lose PTEN expression in CNS microenvironment. This process promotes cell growth and proliferation by PI3K/AKT activation and increased microglial CCL2 chemokine production (31).

Pharmacological inhibition of PI3K/AKT pathway decreases the malignant cell proliferation by increasing apoptosis (31-33). In addition, chemokine receptor CCR4 is highly expressed in BM compared with primary tumor cells and is associated with increased risk of brain dissemination in melanoma. CCR4 is a receptor for CCL12 and CCL17 that promote BBB penetration (27). CCR4, their ligand CCL22 and CCL17 can be included in the specific pattern of BM and can be a target molecule in order to limit BM in melanoma (34). 


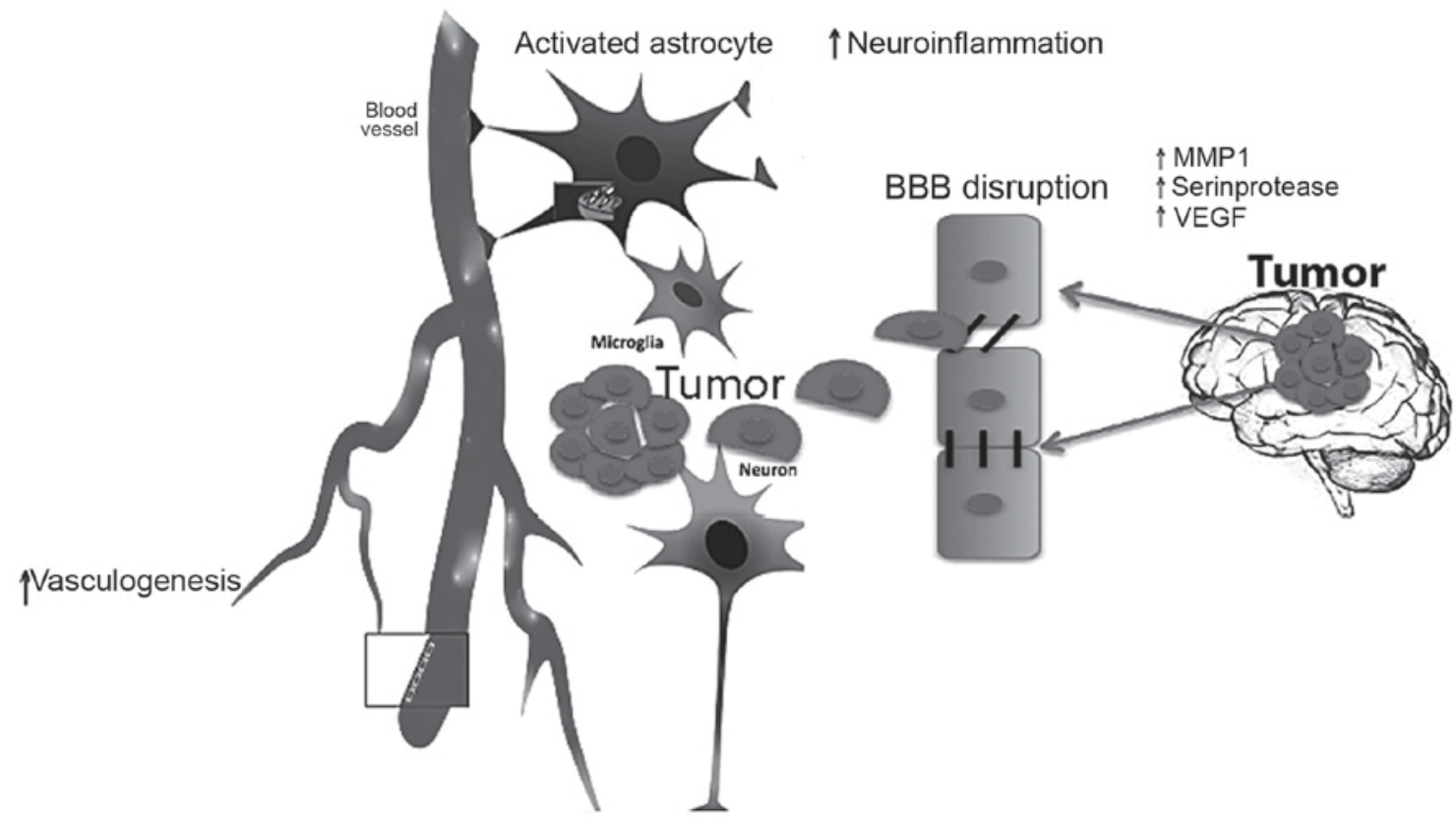

Figure 1. Brain metastases: i) Need a protective environment; ii) promote vasculogenesis; and iii) neurovascular niche is crucial for tumor development and survival.

Melanoma progression is also associated with epigenetic changes targeting key cellular pathways. The most important epigenetic changes in melanoma progression are: i) histone modifications, ii) non-coding RNA expression; and iii) DNA methylation (35).

The small non-coding RNAs (miRNAs) that regulate gene expression can promote the tumor progression or act as tumor suppressors. Previous studies showed that the miR-15b expression is increased in melanoma cells of highly agressive tumors. In contrast, downregulation of miR-15b expression can decrease tumor progression, increase the apoptotic pathways and can be an independent predictive marker of disease progression (36). However, this potential of small non-coding RNAs has not been yet fully explored. Due to large number of genes that can be regulated by a miRNA molecule the specificity of cellular response can be decreased, which makes this molecules difficult to be used in clinical settings. A research study done by Hanniford et al, highlighted in three patient cohorts a prognostic miRNA pattern (miR-150-5p, miR15b-5p, miR-16-5p and miR-374b-3p) that, according to the stage of the disease, can predict the risk of developing brain metastases (37).

Epigenetic modification of genes involved in immune defence or apoptosis can be a powerful therapeutic target in order to control the melanoma cell dissemination. The DNA hypermethylation or histone acetylation status can predict tumor progression by deregulating key signalling pathways that control cell outcome, apoptosis or inflammation. Research studies showed that demethylation of pro-apoptotic genes can reactivate cell death pathways, but this mechanism is not fully explored in melanoma cells (38).

Recent findings showed that the exosomes are key players in malignant cell survival and interaction with the brain envinronment. Exosomes are small vesicles $(50-140 \mathrm{~nm})$ formed by mRNA, microRNAs and proteins from donor cells (miRNAs) surrounded by a lipid bilayer. Exosomes secreted from many cells including tumor cells and are an important player in tumor progression strategy and drug response. The mechanism of tumor progression exosome mediated pathways consists in the ability to develop an environment that can support angiogenesis, tumor progression and premetastatic niche formation (39). On the other hand, exosomes can promote tumor resistance and progression by modulating the immune system, and by altering the genetic and epigenetic factors (40).

Active molecules, such as astrocytic-derived microRNAs are secreted as exosomes and they target malignant PTEN expression in order to promote BM. Astrocytic exosome inhibition can prevent BM (41). A multicentre study on 318 patients with breast cancer ( 84 with $\mathrm{BM}$ ) highlighted that fibroblast growth factor-inducible protein 14 (FN14) and GRP94 are prediction/prognosis markers that can be used as therapeutic targets in BM patients (42). However, this study was performed in breast cancer patients and the results should be carefully extrapolated in BM from melanoma due to the specific molecular signature of the melanoma cells.

Other studies have identified some signalling molecules, which are associated with penetration of the BBB in BM. Such molecules as melanotransferrin or the activator of transcription 3 (STAT3) can facilitate the BBB crossing and it has a predictive potential for BM formation $(42,43)$.

However, there is a difference between the molecular signature of primary melanoma, CNS secondary tumors and non-CNS secondary tumors. Melanomas that express integrins are associated with non-CNS (e.g., lung, lymph node) metastases. CNS metastases are associated with expression of p75 NGF receptor (NGF-R) that promotes brain metastases (44).

Melanomas express a large number of genes that may appear in the normal brain. This patter can contribute to the mechanism of brain metastases in melanoma, or can be due to the common neural crest origin of melanomas (44). 
Table I. Completed clinical trials for melanoma BM.

\begin{tabular}{|c|c|c|c|c|c|}
\hline Study ID & Therapy & Targeted pathways & Genetic mutation & Combined therapy & Refs. \\
\hline NCT02000739 & $\begin{array}{l}\text { Genetically } \\
\text { informed } \\
\text { therapy }\end{array}$ & $\begin{array}{l}\text { Comercial available drug } \\
\text { that specifically target } \\
\text { the genetic mutation }\end{array}$ & & No & (29) \\
\hline NCT01378975 & $\begin{array}{l}\text { Drug therapy } \\
\text { (vemurafenib) }\end{array}$ & $\begin{array}{l}\text { B-Raf/MEK/ } \\
\text { ERK pathway }\end{array}$ & $\begin{array}{l}\text { V600E BRAF } \\
\text { mutation }\end{array}$ & No & (30) \\
\hline NCT02230306 & Drug therapy & $\begin{array}{l}\text { MAPK and } \\
\text { B-Raf pathway }\end{array}$ & $\begin{array}{l}\text { V600E BRAF } \\
\text { mutation }\end{array}$ & Cobimetinib/vemurafenib & (32) \\
\hline NCT02097732 & $\begin{array}{l}\text { Surgery/ } \\
\text { drug therapy }\end{array}$ & Immune system & $\begin{array}{l}\text { CTL4A protein } \\
\text { receptor }\end{array}$ & $\begin{array}{l}\text { Stereotactic radiosurgery/ } \\
\text { ipilimumab }\end{array}$ & $(35)$ \\
\hline NCT01721603 & $\begin{array}{l}\text { Surgery/ } \\
\text { drug therapy }\end{array}$ & $\begin{array}{l}\text { B-Raf/MEK/ERK pathway; } \\
\text { MAPK pathway }\end{array}$ & $\begin{array}{l}\text { V600E BRAF } \\
\text { mutation }\end{array}$ & $\begin{array}{l}\text { Dabrafenib/radiosurgery; } \\
\text { Trametinib/radiosurgery }\end{array}$ & (33) \\
\hline NCT00623766 & $\begin{array}{l}\text { Combined } \\
\text { drug therapy }\end{array}$ & Immune system & & Ipilimumab/corticosteroids & $(36,38-40)$ \\
\hline NCT01266967 & Drug therapy & $\begin{array}{l}\text { B-Raf/MEK/ } \\
\text { ERK pathway }\end{array}$ & $\begin{array}{l}\text { V600E BRAF } \\
\text { mutation }\end{array}$ & Dabrafenib & $(19,41,42)$ \\
\hline
\end{tabular}

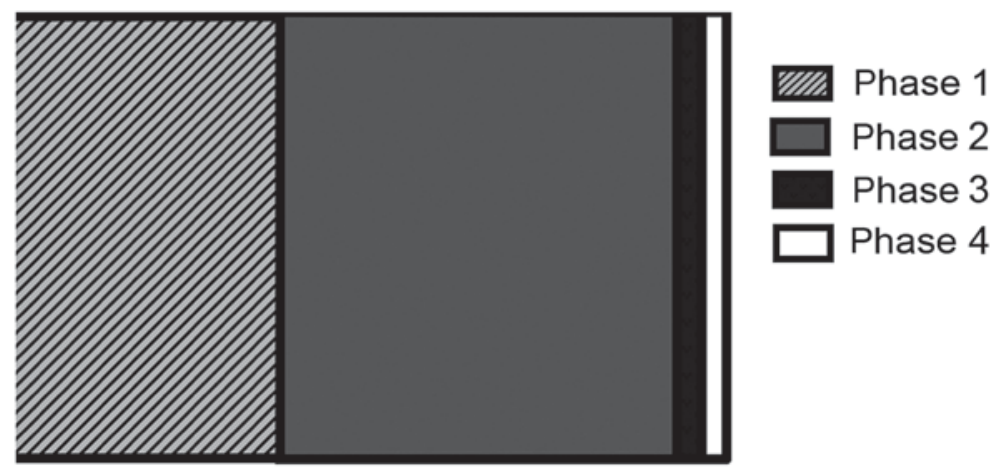

Figure 2. From 88 registered clinical trials, 22 studies were in phase 1; 51 studies in phase 2; 5 studies in phase 3; and only 2 studies in phase 4.

\section{Translational and clinical studies targeting BM specific molecules in melanoma}

In the last decade many clinical trials on melanoma therapeutic strategies were successfully implemented, but only few of them have included BM patients. From 2,129 registered studies (www.clinicaltrials.com) on melanoma only 88 studies were performed on BM patients and 17 studies are completed (Table I). From these studies, 22 studies are in phase 1, 51 studies in phase 2, 5 studies in phase 3 and only 2 studies in phase 4 (Fig. 2).

The genetic pattern of brain secondary tumors can differ significantly between patients and they can also differ from the original tumor. Some studies were focused on establishing the most efficient available drugs according to the genetic mutation that was found by gene sequence analysis (45). Genomic based therapeutic decisions were established as efficient tools in different tumors. Only one clinical trial on genetic informed therapy in melanoma BM was registered (NCT02000739) but unfortunately has been retracted. However, the most aggressive melanomas are associated with BRAF mutation. Many clinical trials were addressed to B-Raf pathway inhibition. A phase 2 clinical trial performed between 2011 and 2015 on 146 patients using an inhibitor of B-Raf pathway (vemurafenib) has showed that vemurafenib is an efficient drug for $\mathrm{BM}$ with B-raf mutation but not all BM are vemurafenib sensitive $(46,47)$. Therefore, other clinical trials were designed to combine multiple pathway inhibitors or to combine surgical and systemic therapy (e.g., immunotherapy). In these clinical studies combined therapy targeted the co-inhibition of B-Raf pathway with MAPK and PI3K-AKT pathway $(47,48)$. Combination of B-Raf inhibitor (vemurafenib) with MEK inhibitor (cobimetinib) showed a median progression-free survival of 9.9 months, which is 3 month longer than control group. Also, the average of complete response was higher in combined group (10\%) compared to control group (4\%) (48). The association between radiosurgery and B-Raf inhibitor drugs did not show any benefits and it was associated with high radiation necrosis risk (49).

PI3K pathway plays an important role in the melanoma progression. Preclinical models have proved that PTEN acts in combination with BRAF V600E in order to promote melanoma 
progression. Targeting MEK and the PI3K pathways in animal models can inhibit tumorigenesis (50). Clinical trial that target PI3K and MEK pathway are ongoing. Also, CDK4 mutations that were successfully performed on transgenic mice are now tested on clinical trials (51).

\section{Conclusion}

For a long period of time, the only available therapeutic option for BM associated with melanoma was the surgery and/or the radiotherapy. Due to technological progress, new therapeutic options have started to show benefits. Immunotherapy, molecularly targeted drugs or personalized gene therapies are new promising tools in BM clinical management. However, the other aspect of this new era is the increased risk of BM since the survival time of patient with melanoma is increased. Therefore, a new challenge consists in the management of latest stage complications like BM. However, this is not an easy task since we have substantial evidence that proves the increased genomic variability between different locations of tumors.

However, many studies have showed that the tumor cells undergo different mutations after interacting with a new environment. This behaviour explains partially the failure of different therapeutic strategies. Mutations of different signalling pathways such as the PI3K/ATK/mTOR pathway can be key factors that can provide new therapeutic strategies in order to limit or prevent BM in melanoma. However, many clinical trials failed to show a real benefit in BM therapy. One explanation of this is the lack of standardisation in clinical trial design.

Many preclinical studies were performed on cell cultures and did not prove the same efficacy in clinical trials. The design of representative preclinical models is crucial for successful translational results. The multimodal approach of $\mathrm{BM}$ melanoma can offer a new perspective in BM treatment associated to melanoma. Further research is needed in order to establish the therapeutic window and association of available targeted drugs taking into account the dynamic and genetic variability of BM.

\section{Acknowledgements}

Not applicable.

\section{Funding}

No funding was received.

\section{Availability of data and materials}

The datasets used and/or analyzed during the current study are available from the corresponding author on reasonable request.

\section{Authors' contributions}

$\mathrm{AMB}, \mathrm{AOD}$ and $\mathrm{DC}$ contributed to drafting and writing the manuscript. GI, SLI and AI were responsible for the collection of relevant literatures. CA, RDM and DEB contributed to the conception of the figure, interpreted the results and revised the manuscript critically for important intellectual content. All authors read and approved the final manuscript.

\section{Ethics approval and consent to participate}

Not applicable.

\section{Patient consent for publication}

Not applicable.

\section{Competing interests}

The authors declare that they have no competing interests.

\section{References}

1. Nussbaum L, Hogea LM, Călina D, Andreescu N, Grădinaru L, Stefănescu R and Puiu M: Modern treatment approaches in psychoses. Pharmacogenetic, neuroimagistic and clinical implications. Farmacia 65: 75-81, 2017.

2. Neagu M, Caruntu C, Constantin C, Boda D, Zurac S, Spandidos DA and Tsatsakis AM: Chemically induced skin carcinogenesis: Updates in experimental models (Review). Oncol Rep 35: 2516-2528, 2016.

3. Gugger A, Barnhill RL, Seifert B, Dehler S, Moch H, Lugassy C, Marques-Maggio E, Rushing JE and Mihic-Probst D: Cutaneous melanoma with brain metastasis: Report of 193 patients with new observations. PLoS One 11: e0156115, 2016.

4. Weber JS, O'Day S, Urba W, Powderly J, Nichol G, Yellin M, Snively J and Hersh E: Phase I/II study of ipilimumab for patients with metastatic melanoma. J Clin Oncol 26: 5950-5956, 2008.

5. Joosse A, de Vries E, Eckel R, Nijsten T, Eggermont AM, Hölzel D, Coebergh JW and Engel J; Munich Melanoma Group: Gender differences in melanoma survival: Female patients have a decreased risk of metastasis. J Invest Dermatol 131: 719-726, 2011.

6. Baghirov H, Snipstad S, Sulheim E, Berg S, Hansen R, Thorsen F, Mørch Y, Davies CL and Åslund AK: Ultrasound-mediated delivery and distribution of polymeric nanoparticles in the normal brain parenchyma of a metastatic brain tumour model. PLoS One 13: e0191102, 2018.

7. Luss AL, Kulikov PP, Romme SB, Andersen CL, Pennisi CP, Docea AO, Kuskov AN, Velonia K, Mezhuev YO, Shtilman MI, et al: Nanosized carriers based on amphiphilic poly-N-vinyl2-pyrrolidone for intranuclear drug delivery. Nanomedicine (Lond) 13: 703-715, 2018.

8. Engin AB, Nikitovic D, Neagu M, Henrich-Noack P, Docea AO, Shtilman MI, Golokhvast K and Tsatsakis AM: Mechanistic understanding of nanoparticles' interactions with extracellular matrix: The cell and immune system. Part Fibre Toxicol 14: 22, 2017.

9. Neagu M, Piperigkou Z, Karamanou K, Engin AB, Docea AO, Constantin C, Negrei C, Nikitovic D and Tsatsakis A: Protein bio-corona: Critical issue in immune nanotoxicology. Arch Toxicol 91: 1031-1048, 2017.

10. Piperigkou Z, Karamanou K, Engin AB, Gialeli C, Docea AO, Vynios DH, Pavão MS, Golokhvast KS, Shtilman MI, Argiris A, et al: Emerging aspects of nanotoxicology in health and disease: From agriculture and food sector to cancer therapeutics. Food Chem Toxicol 91: 42-57, 2016.

11. Pinzaru I, Coricovac D, Dehelean C, Moacă EA, Mioc M, Baderca F, Sizemore I, Brittle S, Marti D, Calina CD, et al: Stable PEG-coated silver nanoparticles - A comprehensive toxicological profile. Food Chem Toxicol 111: 546-556, 2018.

12. Wilhelm I, Molnár J, Fazakas C, Haskó J and Krizbai IA: Role of the blood-brain barrier in the formation of brain metastases. Int $\mathrm{J}$ Mol Sci 14: 1383-1411, 2013.

13. Soto MS, Serres S, Anthony DC and Sibson NR: Functional role of endothelial adhesion molecules in the early stages of brain metastasis. Neuro Oncol 16: 540-551, 2014.

14. Fan J, Cai B, Zeng M, Hao Y, Giancotti FG and Fu BM: Integrin $\beta 4$ signaling promotes mammary tumor cell adhesion to brain microvascular endothelium by inducing ErbB2-mediated secretion of VEGF. Ann Biomed Eng 39: 2223-2241, 2011.

15. Gorantla V, Kirkwood JM and Tawbi HA: Melanoma brain metastases: An unmet challenge in the era of active therapy. Curr Oncol Rep 15: 483-491, 2013. 
16. Fazakas C, Wilhelm I, Nagyoszi P, Farkas AE, Haskó J, Molnár J, Bauer H, Bauer HC, Ayaydin F, Dung NT, et al: Transmigration of melanoma cells through the blood-brain barrier: Role of endothelial tight junctions and melanoma-released serine proteases. PLoS One 6: e20758, 2011.

17. Izraely S, Sagi-Assif O, Klein A, Meshel T, Tsarfaty G, Pasmanik-Chor M, Nahmias C, Couraud PO, Ateh E, Bryant JL, et al: The metastatic microenvironment: Brain-residing melanoma metastasis and dormant micrometastasis. Int J Cancer 131: 1071-1082, 2012.

18. Klein A, Schwartz H, Sagi-Assif O, Meshel T, Izraely S, Ben Menachem S, Bengaiev R, Ben-Shmuel A, Nahmias C, Couraud PO, et al: Astrocytes facilitate melanoma brain metastasis via secretion of IL-23. J Pathol 236: 116-127, 2015.

19. Fidler IJ: The role of the organ microenvironment in brain metastasis. Semin Cancer Biol 21: 107-112, 2011.

20. Valiente M, Obenauf AC, Jin X, Chen Q, Zhang XH, Lee DJ, Chaft JE, Kris MG, Huse JT, Brogi E, et al: Serpins promote cancer cell survival and vascular co-option in brain metastasis. Cell 156: 1002-1016, 2014.

21. Schwartz H, Blacher E, Amer M, Livneh N, Abramovitz L, Klein A, Ben-Shushan D, Soffer S, Blazquez R, Barrantes-Freer A, et al: Incipient melanoma brain metastases instigate astrogliosis and neuroinflammation. Cancer Res 76: 4359-4371, 2016.

22. Zurac S, Neagu M, Constantin C, Cioplea M, Nedelcu R, Bastian A, Popp C, Nichita L, Andrei R, Tebeica T, et al: Variations in the expression of TIMP1, TIMP2 and TIMP3 in cutaneous melanoma with regression and their possible function as prognostic predictors. Oncol Lett 11: 3354-3360, 2016.

23. Lupu M, Caruntu A, Caruntu C, Papagheorghe LM, Ilie MA, Voiculescu V, Boda D, Constantin C, Tanase C, Sifaki M, et al: Neuroendocrine factors: The missing link in non melanoma skin cancer (Review). Oncol Rep 38: 1327-1340, 2017.

24. Caruntu C, Boda D, Constantin C, Caruntu A and Neagu M: Catecholamines increase in vitro proliferation of murine B16F10 melanoma cells. Acta Endocrinol (Buc) 4: 545-558, 2014

25. Diaconeasa A, Boda D, Solovan C, Enescu DM, Vîlcea AM and Zurac S: Histopathologic features of Spitzoid lesions in different age groups. Rom J Morphol Embryol 54: 51-62, 2013.

26. Boda D: Cellomics as integrative omics for cancer. Curr Proteomics 10: 237-245, 2013.

27. Nieder C, Marienhagen K, Geinitz H and Grosu AL: Can current prognostic scores reliably guide treatment decisions in patients with brain metastases from malignant melanoma? J Cancer Res Ther 7: 47-51, 2011.

28. Winkler F: The brain metastatic niche. J Mol Med (Berl) 93 1213-1220, 2015

29. Kim HY, Lee H, Kim SH, Jin H, Bae J and Choi HK: Discovery of potential biomarkers in human melanoma cells with different metastatic potential by metabolic and lipidomic profiling. Sci Rep 7: 8864, 2017.

30. Peltier J, O'Neill A and Schaffer DV: PI3K/Akt and CREB regulate adult neural hippocampal progenitor proliferation and differentiation. Dev Neurobiol 67: 1348-1361, 2007.

31. Zhang L, Zhang S, Yao J, Lowery FJ, Zhang Q, Huang WC, Li P, Li M, Wang X, Zhang C, et al: Microenvironment-induced PTEN loss by exosomal microRNA primes brain metastasis outgrowth Nature 527: 100-104, 2015.

32. Niessner H, Schmitz J, Tabatabai G, Schmid MA, Calaminus C, Sinnberg T, Weide B, Eigentler KT, Garbe C, Schittek B, et al: PI3K pathway inhibition achieves potent antitumor activity in melanoma brain metastases in vitro and in vivo. Clin Cancer Res 22: 5818-5828, 2016.

33. Niessner H, Forschner A, Klumpp B, Honegger JB, Witte M, Bornemann A, Dummer R, Adam A, Bauer J, Tabatabai G, et al: Targeting hyperactivation of the AKT survival pathway to overcome therapy resistance of melanoma brain metastases Cancer Med 2: 76-85, 2013

34. Davies MA, Stemke-Hale K, Lin E, Tellez C, Deng W, Gopal YN, Woodman SE, Calderone TC, Ju Z, Lazar AJ, et al: Integrated molecular and clinical analysis of AKT activation in metastatic melanoma. Clin Cancer Res 15: 7538-7546, 2009.
35. Marzese DM, Witz IP, Kelly DF and Hoon DS: Epigenomic landscape of melanoma progression to brain metastasis: Unexplored therapeutic alternatives. Epigenomics 7: 1303-1311, 2015.

36. Satzger I, Mattern A, Kuettler U, Weinspach D, Voelker B, Kapp A and Gutzmer R: MicroRNA-15b represents an independent prognostic parameter and is correlated with tumor cell proliferation and apoptosis in malignant melanoma. Int $\mathrm{J}$ Cancer 126: 2553-2562,2010.

37. Hanniford D, Zhong J, Koetz L, Gaziel-Sovran A, Lackaye DJ, Shang S, Pavlick A, Shapiro R, Berman R, Darvishian F, et al: A miRNA-based signature detected in primary melanoma tissue predicts development of brain metastasis. Clin Cancer Res 21: 4903-4912, 2015.

38. Sigalotti L, Covre A, Fratta E, Parisi G, Colizzi F, Rizzo A, Danielli R, Nicolay HJ, Coral S and Maio M: Epigenetics of human cutaneous melanoma: Setting the stage for new therapeutic strategies. J Transl Med 8: 56, 2010.

39. Wang Z, Chen JQ, Liu JL and Tian L: Exosomes in tumor microenvironment: Novel transporters and biomarkers. J Transl Med 14: 297, 2016

40. Abak A, Abhari A and Rahimzadeh S: Exosomes in cancer: Small vesicular transporters for cancer progression and metastasis, biomarkers in cancer therapeutics. PeerJ 6: e4763, 2018.

41. Martínez-Aranda A, Hernández V, Guney E, Muixí L, Foj R, Baixeras N, Cuadras D, Moreno V, Urruticoechea A, Gil M, et al: FN14 and GRP94 expression are prognostic/predictive biomarkers of brain metastasis outcome that open up new therapeutic strategies. Oncotarget 6: 44254-44273, 2015.

42. Klein A, Sagi-Assif O, Meshel T, Telerman A, Izraely S, Ben-Menachem S, Bayry J, Marzese DM, Ohe S, Hoon DS, et al: CCR4 is a determinant of melanoma brain metastasis. Oncotarget 8: 31079-31091, 2017.

43. Rolland Y, Demeule M, Fenart L and Béliveau R: Inhibition of melanoma brain metastasis by targeting melanotransferrin at the cell surface. Pigment Cell Melanoma Res 22: 86-98, 2009.

44. Zbytek B, Carlson JA, Granese J, Ross J, Mihm MC Jr and Slominski A: Current concepts of metastasis in melanoma. Expert Rev Dermatol 3: 569-585, 2008.

45. Xie TX, Huang FJ, Aldape KD, Kang SH, Liu M, Gershenwald JE, Xie K, Sawaya R and Huang S: Activation of stat 3 in human melanoma promotes brain metastasis. Cancer Res 66: 3188-3196, 2006.

46. Tafe LJ, Gorlov IP, de Abreu FB, Lefferts JA, Liu X, Pettus JR, Marotti JD, Bloch KJ, Memoli VA, Suriawinata AA, et al: Implementation of a molecular tumor board: The impact on treatment decisions for 35 patients evaluated at Dartmouth-Hitchcock Medical Center. Oncologist 20: 1011-1018, 2015.

47. Chowdhary M, Patel KR, Danish HH, Lawson DH and Khan MK: BRAF inhibitors and radiotherapy for melanoma brain metastases: Potential advantages and disadvantages of combination therapy. OncoTargets Ther 9: 7149-7159, 2016

48. Harding JJ, Catalanotti F, Munhoz RR, Cheng DT, Yaqubie A, Kelly N, McDermott GC, Kersellius R, Merghoub T, Lacouture ME, et al: A Retrospective evaluation of vemurafenib as treatment for BRAF-mutant melanoma brain metastases. Oncologist 20: 789-797, 2015

49. Larkin J, Ascierto PA, Dréno B, Atkinson V, Liszkay G, Maio M, Mandalà M, Demidov L, Stroyakovskiy D, Thomas L, et al: Combined vemurafenib and cobimetinib in BRAF-mutated melanoma. N Engl J Med 371: 1867-1876, 2014

50. Dankort D, Curley DP, Cartlidge RA, Nelson B, Karnezis AN, Damsky WE Jr, You MJ, DePinho RA, McMahon M and Bosenberg M: Braf(V600E) cooperates with Pten loss to induce metastatic melanoma. Nat Genet 41: 544-552, 2009.

51. Sotillo R, García JF, Ortega S, Martin J, Dubus P, Barbacid M and Malumbres M: Invasive melanoma in Cdk4-targeted mice. Proc Natl Acad Sci USA 98: 13312-13317, 2001. 